\title{
Grasa epicárdica y esteatosis hepática como marcadores de riesgo cardiovascular
}

\author{
Epicardial Fat and Hepatic Steatosis as Cardiovascular Risk Markers

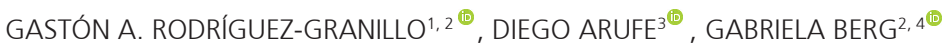

\section{RESUMEN}

El tejido adiposo epicardico (TAE) es un tejido metabólicamente activo que ha cobrado gran interés en la última década como marcador de riesgo cardiovascular. El TAE se relaciona con la producción de citoquinas proinflamatorias y de ácidos grasos libres, con la promoción de un estado de hipercoagulabilidad, y con numerosos factores de riesgo cardiometabólico. Existe una íntima relación entre las arterias coronarias y el TAE, no solo anatómica, sino en cuanto a aspectos fisiológicos bidireccionales de regulación paracrina. Además, numerosos estudios han encontrado una relación entre el TAE y la presencia de disfunción endotelial, ateromatosis no obstructiva, estrés oxidativo, fibrilación auricular, y disfunción diastólica.

En paralelo, existe una estrecha relación entre la esteatosis hepática (la enfermedad hepática crónica más frecuente), la ateromatosis coronaria, y el riesgo cardiovascular. Una de las características interesantes de la esteatosis hepática y diferenciales con respecto a la enfermedad coronaria es su carácter dinámico y, en cierta medida, reversible.

A pesar de las asociaciones descriptas con la ateromatosis y con el riesgo cardiovascular, y de su evaluación sencilla a partir de métodos de imagen no invasivos, la grasa epicárdica y el hígado graso no alcohólico son raramente considerados como marcadores de riesgo en la práctica clínica.

Palabras clave: Aterosclerosis - Tejido Adiposo - Índice de masa corporal - Tomografía Computarizada - Hígado graso - Inflamación - Pericardio - Factores de Riesgo

\begin{abstract}
Epicardial adipose tissue (EAT) is a metabolically active tissue which has raised great interest in the last decade as a cardiovascular risk marker. It is related with the production of proinflammatory cytokines and free fatty acids, the promotion of a state of hypercoagulability and with numerous cardiometabolic risk factors. Between EAT and coronary arteries, there is not only an intimate anatomical association, but also bidirectional physiological aspects of paracrine regulation. In addition, several studies have found a relationship between EAT and endothelial dysfunction, non-obstructive atheromatosis, oxidative stress, atrial fibrillation and diastolic dysfunction.

Parallel to these findings, there is a tight association between hepatic steatosis (the most prevalent chronic hepatic disease), coronary atheromatosis and cardiovascular risk. One of the interesting and differential characteristics of hepatic steatosis with respect to coronary artery disease is its dynamic, and to a certain point reversible, character.

Despite their association with atheromatosis and cardiovascular risk and simple assessment from non-invasive imaging methods, epicardial fat and non-alcoholic fatty liver are seldom considered as risk markers in clinical practice.
\end{abstract}

Key words: Atherosclerosis - Adipose Tissue - Body Mass Index - Computed Tomography - Fatty Liver - Inflammation - Pericardium - Risk Factors

\section{INTRODUCCIÓN}

El tejido adiposo epicárdico (TAE) es el depósito graso visceral intratorácico localizado entre el miocardio y el pericardio, en íntimo contacto con las arterias coronarias en todo su trayecto. Considerado históricamente como un simple depósito de energía, el TAE es un tejido metabólicamente activo que ha cobrado gran interés en la última década como marcador de riesgo cardiovascular. (1) Tanto el TAE como el tejido adiposo visceral abdominal, de mismo origen embriológico, se relacionan con la producción de citoquinas proinflama- torias y de ácidos grasos libres (AGL), con la promoción de un estado de hipercoagulabilidad, y con numerosos factores de riesgo cardiometabólico. (2-4) En particular, los pacientes diabéticos evidencian un mayor volumen de TAE, con un perfil metabólicamente más activo y proinflamatorio independientemente de los otros factores de riesgo cardiovasculares (FRC). (5-7)

La función del TAE en el desarrollo y progresión de la ateromatosis coronaria ha sido demostrada no solo mediante su asociación con la gravedad, sino también con la presencia y extensión de ateromatosis no obstructiva. $(8,9)$ En paralelo, numerosos estudios

Rev Argent Cardiol 2020;88:343-354. http://dx.doi.org/10.7775/rac.es.v88.i4.18387

Dirección para separatas: Instituto Medico ENERI, Clínica La Sagrada Familia - Av. Libertador 6647 (C1428ARJ) Buenos Aires, Argentina - E-mail: grodriguezgranillo@gmail.com.

\footnotetext{
${ }^{1}$ Instituto Medico ENERI, Clínica La Sagrada Familia

${ }^{2}$ Consejo Nacional de Investigaciones Científicas y Técnicas (CONICET)

${ }^{3}$ Hospital Universitario Austral. Unidad de Hepatología y Trasplante Hepático. Sanatorio Sagrado Corazón. Unidad de Hepatología y Trasplante Hepático.

${ }^{4}$ Universidad de Buenos Aires, Facultad de Farmacia y Bioquímica, Instituto de Fisiopatología y Bioquímica Clínica (INFIBIOC), Departamento de

Bioquímica Clínica, Laboratorio de Lípidos y Aterosclerosis, Buenos Aires, Argentina
} 
han encontrado una relación entre dichos depósitos de grasa y la presencia de disfunción endotelial, fibrilación auricular y disfunción diastólica. (10-13) Más recientemente, se ha descubierto que el TAE no es homogéneo en cuanto a su distribución y composición, y que dichas diferencias se asocian a cambios regionales de la composición de las placas ateroescleróticas adyacentes, particularmente en cuanto a la presencia de inflamación coronaria. (14-16)

En paralelo, existe una estrecha relación entre la esteatosis hepática (EH), la ateromatosis coronaria, y el riesgo cardiovascular. La EH es la enfermedad hepática crónica más frecuente, con prevalencia estimada entre el $20 \%$ y el $30 \%$ de la población general y la segunda causa de trasplante hepático. (17) La EH se encuentra asociada de forma estrecha con los distintos componentes del síndrome metabólico. (18) Asimismo, estudios recientes han demostrado una relación entre la $\mathrm{EH}$ y la grasa visceral. (4) Sin embargo, se desconoce si la EH ejerce un papel activo en el desarrollo y progresión de la ateromatosis, o si su presencia solo refleja la coexistencia de otros marcadores de riesgo cardiometabólico.

Considerando que el riesgo cardiovascular residual a pesar de la implementación de las mejores estrategias de prevención se atribuye en parte a inflamación coronaria, la incorporación de herramientas de monitoreo y de marcadores de vulnerabilidad que permitan valorar tanto la inflamación aguda como los cambios crónicos vasculares y perivasculares es altamente deseada. (19-21)

\section{Limitaciones de los marcadores generales de obesidad}

La morbimortalidad cardiovascular en pacientes obesos es más elevada que la población general; esto está vinculado en mayor medida a su asociación con múltiples FRC. $(22,23)$ Sin embargo, los marcadores generales de adiposidad como el índice de masa corporal (IMC) presentan numerosas limitaciones, que, en su conjunto, han llevado a resultados inconsistentes e, incluso, divergentes en cuanto a su capacidad de predicción de eventos. En efecto, numerosos estudios han demostrado una relación negativa entre el IMC y la enfermedad coronaria, así como una debatible asociación entre la obesidad y la sobrevida, particularmente en adultos mayores. $(24,25)$ Este comportamiento controvertido o paradójico se debe en parte a la defectuosa definición de obesidad basada en el IMC, un índice de adiposidad pobre al ser un subrogante más del peso que de la grasa corporal, y al no poder discriminar la proporción de los distintos depósitos regionales de grasa corporal vinculados con perfiles cardiometabólicos y pronósticos divergentes. (26-28) Incluso la circunferencia abdominal presenta limitaciones y en ocasiones resultados contradictorios con respecto a su valor predictivo. (29, 30) Esto posiblemente se atribuya a que la obesidad abdominal fue originalmente definida no por su relación con el riesgo de eventos, sino a partir del IMC como valor de referencia, y a que, a pesar de ser una aproximación a la estimación de la grasa abdominal, no logra distinguir entre grasa subcutánea y visceral. Esta disquisición previamente ignorada es fundamental en vistas de la evidencia actual, ya que, por ejemplo, solo la grasa visceral (y no así la subcutánea) se asocia a la incidencia de insuficiencia cardíaca con función sistólica preservada (ICFSP). (31)

\section{Aspectos fisiopatológicos de la grasa epicárdica}

Además de adipocitos, el tejido adiposo está formado por células estromales (fibroblastos e inflamatorias), y por tejido intersticial. El tejido adiposo produce una gran cantidad de moléculas que regulan numerosos aspectos fisiológicos de los tejidos adyacentes, incluidas citoquinas proinflamatorias y antiinflamatorias, metabolitos de ácidos grasos, y especies reactivas de oxígeno. (32) El $\mathrm{TAE}$, con respecto a otros tejidos adiposos viscerales, se caracteriza por presentar un aumento en la síntesis y catabolismo de ácidos grasos, por lo que ha sido propuesto como grasa buffer que sirve para proteger el corazón contra la esteatosis cardíaca generada por los AGL. (33) Sin embargo, ante la expansión e inflamación del TAE, el "diálogo" entre ambos tejidos se alteraría con interacción entre adipocitoquinas proinflamatorias y el depósito de grasa intramiocárdica, que también acompaña el proceso de insulino-resistencia (IR). (34) Recientemente, hemos demostrado que el TAE de pacientes con enfermedad coronaria y diabetes tipo II presenta mayor actividad de las enzimas encargadas del catabolismo de las lipoproteínas ricas en triglicéridos, lo que promovería un mayor flujo de AGL al interior del tejido, favoreciendo su expansión. (5)

El TAE, particularmente el perivascular, actúa sobre las arterias coronarias de forma paracrina, regulando múltiples aspectos de la biología vascular que incluyen la inflamación (con secreción de citoquinas proinflamatorias como el IL- $1 \beta$, IL-6, y TNF- $\alpha$; y de quimioquinas como la MCP-1), el tono vascular, el estrés oxidativo, y la producción local de óxido nítrico (Figura 1). (32, 35, 36) En cuanto a la inflamación, el TAE puede secretar adipoquinas tanto proinflamatorias (leptina, resistina) como antiinflamatorias (adiponectina), dependiendo el balance entre estas del grado de inflamación y expansión del tejido. Existe evidencia reciente que sugiere que la grasa perivascular (GPV) podría actuar como termómetro de las placas ateroescleróticas subyacentes, registrando cambios locales en el estrés oxidativo y actuando en consecuencia (por ejemplo, secretando adiponectina ante la presencia de un incremento del estrés oxidativo). Además, ante la presencia de inflamación coronaria local y de la consecuente difusión de citoquinas hacia el intersticio perivascular, se reduce el contenido lipídico de los adipocitos (y se incrementa la fase acuosa/edema de la GPV). (37) Por lo tanto, existe una íntima relación entre las arterias coronarias y el TAE, no solo anatómica, sino en cuanto a aspectos fisiológicos bidireccionales (Figura 1). En presencia de un TAE expandido y disfuncional, el efecto proinflamatorio de la grasa epicárdica se ejerce no solo sobre el vaso subyacente, sino que los mediadores proinflamatorios son también liberados al torrente sanguíneo, y si bien el volumen de TAE es 


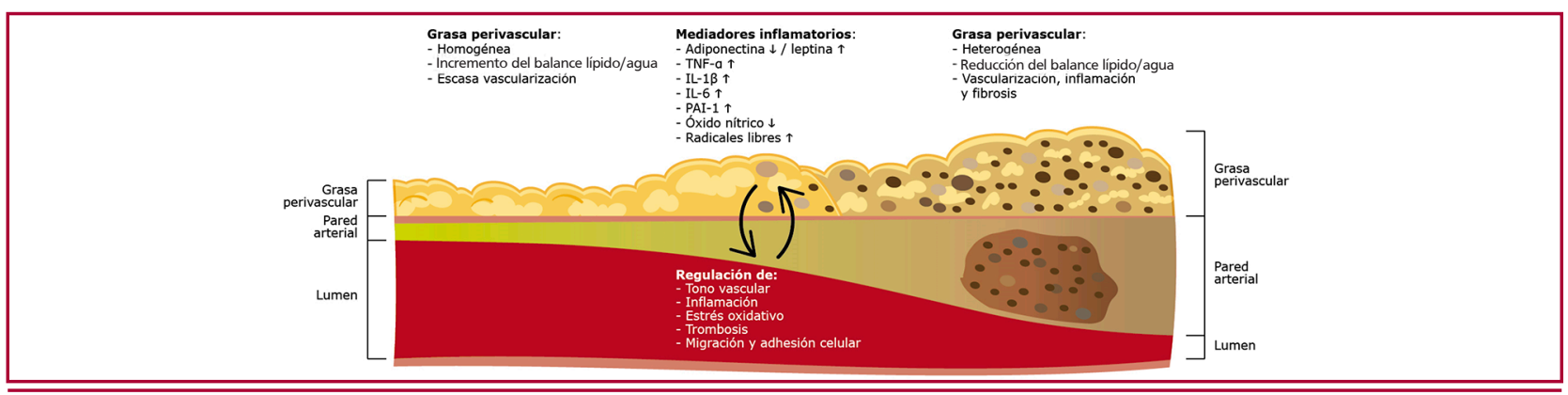

Fig. 1. Función de la grasa perivascular (GPV) en el desarrollo y progresión de la enfermedad coronaria. En el vaso sano, la GPV es homogénea, con adipocitos ricos en lípidos (escaso líquido), escasa vascularización y mínimas células inflamatorias. A medida que se desarrollan las lesiones, la GPV se vuelve heterogénea, los adipocitos reducen su tamaño en virtud de la disminución del contenido lipídico y de una menor diferenciación celular, con incremento de la fase acuosa, y se evidencian incremento de la vascularización, de células inflamatorias (incluida polarización de los macrófagos hacia una mayor concentración de macrófagos activados, M1), y fibrosis. En cuanto a la íntima, se va desarrollando un núcleo lipídico-necrótico con células espumosas y microcalcificaciones, y se evidencia adelgazamiento tanto de la media (con remodelamiento coronario positivo) como de la cubierta fibrosa. Estos fenómenos bidireccionales (desde la pared arterial hacia la GPV, y viceversa) son mediados por múltiples sustancias vasoactivas que regulan el tono vascular, la inflamación, el estrés oxidativo, la coagulación (PAI-1). IL, interleuquina; TNF, factor de necrosis tumoral; PAI, inhibidor del activador del plasminógeno.

mucho menor que el del tejido adiposo visceral abdominal, contribuye también al estado proinflamatorio sistémico. Asimismo, completando el ciclo bidireccional descripto, la inflamación sistémica promueve la acumulación e inflamación de grasa epicárdica. (38) No es casual que, en los pacientes con enfermedades vinculadas a inflamación sistémica, como la psoriasis, artritis reumatoidea, VIH u obesidad, puedan observarse incrementos significativos del TAE. (39-41)

Uno de los aspectos más paradigmáticos y generadores de hipótesis al respecto de la asociación entre la grasa epicárdica y la ateromatosis proviene del estudio de los puentes musculares y de investigaciones en animales, a los que se les resecó la grasa epicárdica. Acerca de lo primero, la ausencia de ateromatosis en el segmento intramiocárdico es característica. (42) En un estudio en el que evaluamos anomalías coronarias por angiografía coronaria por tomografía computada (ACTC) que incluyó 109 puentes musculares, ninguno de los segmentos intramiocárdicos presentó signos de ateromatosis, a pesar de la presencia de enfermedad en el 65\% de los vasos hospederos. (43) En un elegante estudio que incluyó la resección de la grasa epicárdica adyacente al tercio medio de la arteria descendente anterior en cerdos bajo dieta aterogénica y evaluación seriada mediante ultrasonido intravascular, McKenney y cols. identificaron progresión de la ateromatosis de los segmentos proximales y distales, sin cambios significativos en el segmento intervenido, aislado del TAE. (44) Incluso, existe una polarización de los macrófagos encontrados en el TAE de pacientes con enfermedad coronaria en comparación con pacientes sin enfermedad coronaria; los primeros presentaron un mayor cociente de concentración entre macrófagos activados (M1) y aquellos con propiedades antiinflamatorias (M2). (45) En efecto, también se ha demostrado que el TAE de pacientes con enfermedad coronaria presenta mayor densidad vascular, infiltración de macrófagos y actividad de metaloproteasas (MMP) de tipo 2 y 9 , principales enzimas encargadas de degradar las placas ateroscleróticas y vinculadas, además, al remodelamiento coronario (Figura 2). (46) En el TAE, estas

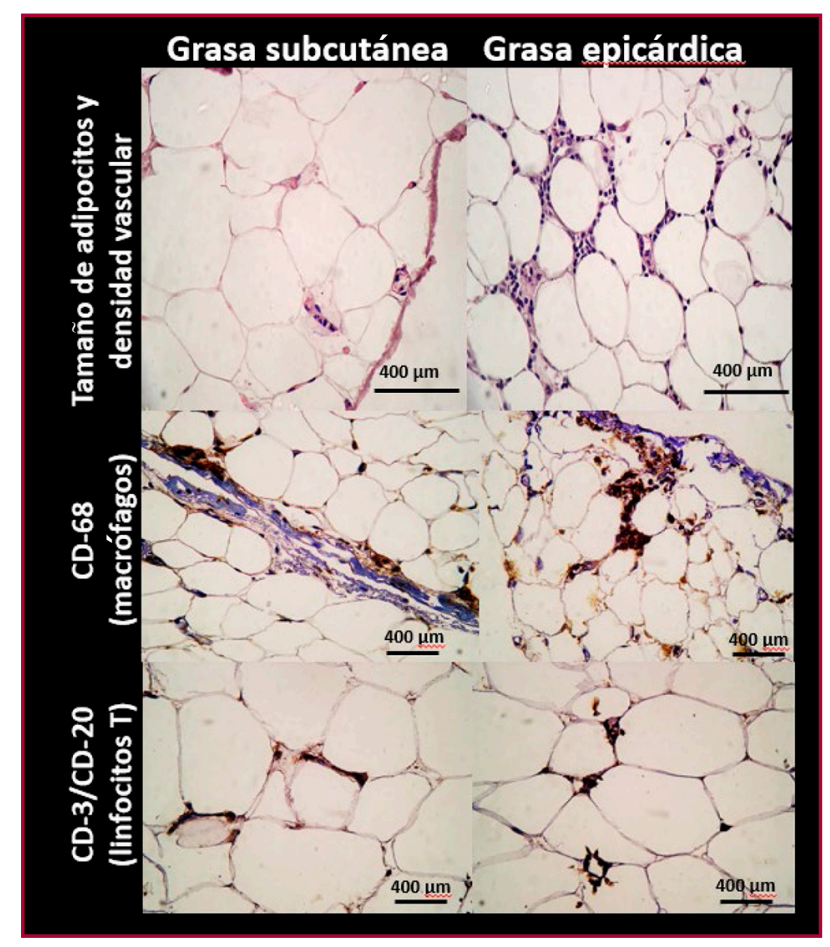

Fig. 2. Características histológicas e infiltrado inflamatorio de tejido adiposo epicárdico (región superior del ventrículo derecho) y subcutáneo (región torácica) obtenidos de pacientes con enfermedad coronaria derivados a cirugía de revascularización de miocardio. Los adipocitos del TAE son de menor tamaño y el tejido se encuentra más vascularizado que el TAS. Por inmunohistoquímica se comprueba que el TAE presenta infiltrado de macrófagos $(C D 68+)$ y de linfocitos $T(C D 3 / C D 20)$. La tinción marrón indica inmunohistoquímica positiva. 
enzimas participan de la expansión del tejido; si bien aún debe ser demostrado si son capaces de migrar hacia las placas ateroscleróticas subyacentes y aumentar su vulnerabilidad.

Por otra parte, y por razones que aún no se encuentran elucidadas, el tejido adiposo subcutáneo ha sido asociado a un menor riesgo de ateromatosis coronaria, periférica y de mortalidad. (47-49) En un trabajo seminal que incluyó pacientes con cirugía electiva de revascularización de miocardio, Mazurek y cols. recolectaron muestras pareadas de TAE adyacentes al tercio proximal de la arteria coronaria derecha y del tejido celular subcutáneo adyacente a las venas safenas, y compararon la expresión de distintos marcadores inflamatorios. (50) En dicho estudio, el TAE mostró niveles significativamente mayores de mediadores inflamatorios que la grasa subcutánea, que incluyen IL-1, IL-6, TNF- $\alpha$, MCP-1, independientemente de la presencia de obesidad, diabetes o de la medicación de base. En cuanto al contenido celular, se identificaron engrosamientos septales e infiltrados celulares inflamatorios en el TAE, incluidos linfocitos T, macrófagos y mastocitos; mientras que no se identificaron células inflamatorias en la grasa subcutánea. Además, no se identificaron asociaciones entre dicha inflamación local y los niveles plasmáticos de citoquinas.

Recientemente, el estudio molecular y lipidómico de biopsias de TAE demostró que los pacientes con enfermedad coronaria presentan un perfil lipidómico con predominio de lípidos proinflamatorios, con mayor concentración de ceramidas, diglicéridos (saturados y monoinsaturados) y monoglicéridos que los pacientes sin enfermedad coronaria. (51)

Por lo tanto, el TAE funciona como un órgano endocrino íntimamente relacionado con el riesgo cardiovascular a través de la regulación de la inflamación.

En paralelo, en un estudio poblacional que incluyó 3291 individuos asintomáticos con edad media de 50 años, Sung y cols. identificaron una asociación entre medidas de grasa visceral (TAE, grasa periaórtica y $\mathrm{EH})$ y la presencia de marcadores inflamatorios como la proteína $\mathrm{C}$ reactiva y el cociente neutrófilos/linfocitos. (4) Además, ese trabajo demostró una asociación entre la gravedad de la $\mathrm{EH}$ y otros marcadores de adiposidad visceral como marcadores inflamatorios.

\section{Aspectos fisiopatológicos de la esteatosis hepática}

$\mathrm{La} \mathrm{EH}$ es el resultado de la acumulación de triglicéridos sintetizados en el hígado, a partir de AGL liberados del tejido adiposo (lipólisis), de exceso de carbohidratos (lipogénesis de novo) o de los triglicéridos provenientes de la dieta. (52) El hígado graso no alcohólico (HGNA) se define como la presencia de esteatosis ( $>5 \%$ de hepatocitos por histología) en ausencia de causas secundarias que puedan generarlo, como consumo crónico de alcohol, infección crónica por hepatitis virales, consumo de medicamentos (ej. corticoides, metotrexato, valproato, etc.) o enfermedades hepáticas autoinmunes. (53) El mecanismo fisiopatológico subyacente para el desarrollo de HGNA se relaciona con alteraciones en el metabolismo intermedio (lípidos y glucosa) y con la IR (18). La insulina es la hormona lipogénica y, en condiciones normales, suprime la producción hepática de glucosa, principalmente eliminando la gluconeogénesis hepática. (54) La IR es mayor en los individuos con HGNA y cumple un papel central en el desarrollo y progresión de la enfermedad. (55) En los pacientes con esteatosis existe una mayor producción hepática de glucosa, en particular a partir de la gluconeogénesis, a pesar de los niveles elevados de insulina. (56) Una de las consecuencias de la IR es el aumento de la lipolisis periférica, principalmente en el tejido adiposo visceral, con aumento de los niveles séricos de AGL, que lleva a un incremento de lípidos tóxicos para el hepatocito, como los diaacilgliceroles y ceramidas, que están involucrados en vías inflamatorias. El espectro histológico del HGNA se extiende desde esteatosis simple, esteatohepatitis, fibrosis y cirrosis (Figura 3).

Si bien el mecanismo no se encuentra del todo elucidado, se cree que la asociación entre el HGNA y la ateroesclerosis se vincula a múltiples factores que implican en distinta medida a la IR, alteración del metabolismo lipoproteico, inflamación de bajo grado, estrés oxidativo, y una disminución de las concentraciones de adiponectina (Figura 3). (57-59)

La activación de la vía NF-kB en pacientes con esteatohepatitis conduce un aumento en la transcripción de diversos genes proinflamatorios. (60) En la misma línea, numerosos marcadores inflamatorios (proteína C reactiva, IL-6 y TNF- $\alpha$ ), oxidativos y procoagulantes (PAI-1, fibrinógeno y factor VII) se encuentran elevados en los pacientes con esteatohepatitis. (61) En un reciente subanálisis del estudio poblacional Multi-Ethnic Study of Atherosclerosis (MESA), que incluyó 668 individuos asintomáticos con HGNA, de los múltiples biomarcadores evaluados (que incluyeron la proteína C reactiva), la IL-6 fue la única identificada como predictor independiente tanto de calcificación coronaria $(\mathrm{CAC}>0)$ como de calcificación coronaria moderadamente extensa (CAC >100). (62) En paralelo, y en línea con los mecanismos descriptos de la grasa epicárdica (Figura 1), los niveles elevados del inhibidor del activador tisular del plasminógeno-1 (PAI-1) en la adultez temprana se asocian de forma independiente con el HGNA en la mitad de la vida. (63)

\section{Evaluación de la grasa epicárdica por métodos de imágenes}

La grasa epicárdica puede ser cuantificada en distinta medida mediante múltiples métodos no invasivos, que incluyen el ecocardiograma transtorácico, la resonancia magnética (RM), la TC, y el PET; la TC sin contraste es el método de referencia debido a su rapidez, disponibilidad, mayor resolución especial, y adquisición volumétrica (Figuras 4 y 5). (64)

La identificación sencilla de la grasa epicárdica mediante la TC (oscilando el límite inferior entre -190 y -250 , y el superior entre -30 y -50 unidades 
Hounsfield) ha llevado al desarrollo de herramientas que permiten la valoración automática del volumen de grasa epicárdica (VGE) utilizando algoritmos de inteligencia artificial con una precisión comparable a revisores expertos. (65) Los límites para la evaluación del VGE no se encuentran bien establecidos, si bien la mayoría de los estudios utiliza la bifurcación de la arteria pulmonar o el punto situado $15 \mathrm{~mm}$ por encima del borde craneal del tronco coronario izquierdo como límite superior y el diafragma como el límite inferior. (64) La evaluación del VGE puede realizarse utilizando tanto adquisiciones de TC cardíaca sin contraste (score de calcio) como mediante ACTC (con contraste), y se sugiere en este último caso subir el umbral de detección a -15 UH, ya que los estudios contrastados suelen subestimar la grasa en aproximadamente un 30\%. (64, 66) Se ha demostrado, además, que las TC de tórax sin contraste convencionales (sin gatillado electrocar- diográfico) (Figura 4) son igualmente reproducibles y presentan el mismo valor predictivo que los estudios gatillados (Figura 5). (67, 68)

Debe mencionarse que el tejido adiposo pericárdico (TAP) incluye tanto el TAE como el paracardíaco (fuera del saco pericárdico). Si bien de valoración más sencilla, estrechamente relacionado con el TAE y con valor pronóstico demostrado en numerosos estudios prospectivos, existen diferencias significativas entre el tejido adiposo paracardíaco y epicárdico en cuanto a su embriología y composición. $(16,69)$

Sea cual fuera la estrategia de medición escogida, una de las mayores limitaciones del uso del VGE como marcador de riesgo en la práctica clínica es la ausencia de estandarización de los valores normales y distintos puntos de corte, habiéndose reportado diferencias significativas según poblaciones, sexo y superficie corporal. $(68,70)$
Fig. 3. Historia natural del hígado graso no alcohólico (HGNA). Se resumen los principales factores de riesgo que condicionan el desarrollo de esteatosis: obesidad, dieta hipercalórica y el consumo de fructosa (componente del azúcar y principal componente de jarabe de maíz de alta fructosa). Los factores que favorecen el desarrollo de esteatohepatitis, fibrosis y cirrosis son la obesidad, los componentes del síndrome metabólico y la diabetes. En el panel inferior, se grafica la relación entre la progresión del HGNA, la aterogénesis y el riesgo de evento cardiovasculares. A medida que progresa la enfermedad hepática aumentan los marcadores de inflamación, factores procoagulantes y lípidos aterogénicos que favorecen el desarrollo de ateromatosis y eventos cardiovasculares.

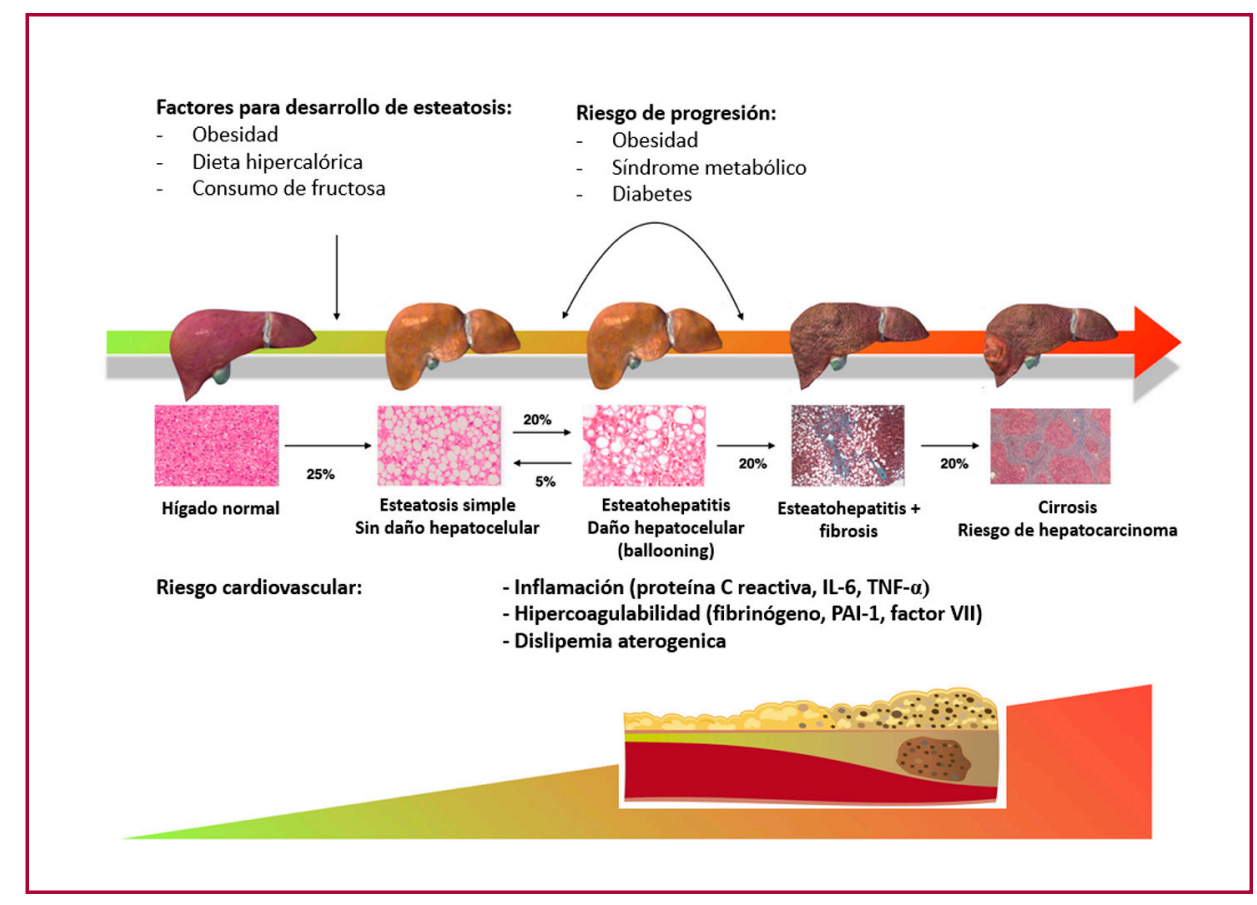

Fig. 4. Cuantificación de la grasa epicárdica, evaluación de la calcificación coronaria e identificación de esteatosis hepática mediante TC de tórax convencional. Nótese la presencia de calcificación en la arteria descendente anterior, con incremento del volumen de la grasa epicárdica (en azul), y esteatosis hepática grave (10 $\mathrm{UH}$, con cociente hígado/bazo de 0,21 ).

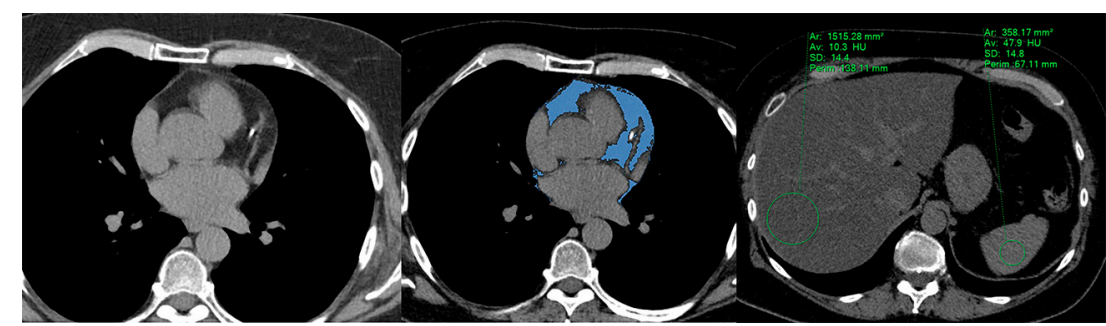




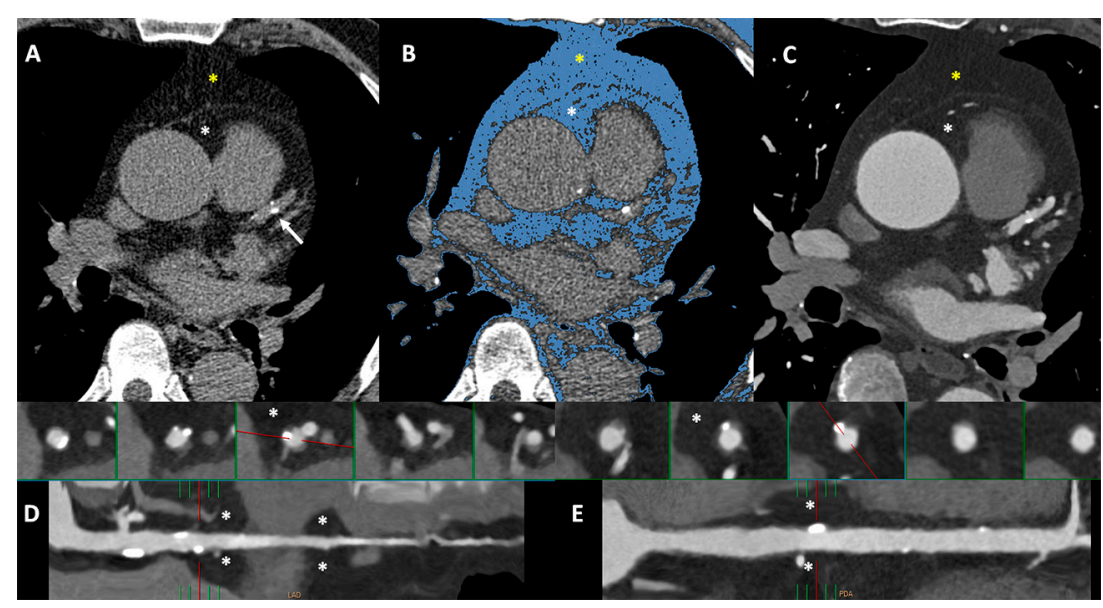

Fig. 5. Score de calcio (paneles A y B) y angiografía coronaria por TC (paneles C-E) en un paciente de sexo masculino de 72 años, hipertenso, con dolor precordial atípico. Tanto el estudio sin contraste (score de calcio) como la angiografía permiten discriminar entre la grasa epicárdica (asterisco blanco) y la grasa paracardíaca (asterisco amarillo), así como calcular su volumen y densidad. Las reconstrucciones multiplanares de las arterias descendente anterior (panel D) y coronaria derecha (panel E) se utilizan para la valoración de la grasa perivascular (asterisco).

Evaluación no invasiva de la esteatosis hepática Existen múltiples métodos no invasivos para la identificación de $\mathrm{EH}$, con distinta precisión, disponibilidad, costo, sensibilidad y especificidad. (71) El ultrasonido convencional es una herramienta ampliamente disponible y de bajo costo, sumamente útil para el tamizaje (screening) mediante evaluación cualitativa. Sin embargo, es de baja sensibilidad para detectar esteatosis histológica menor del 20\%. La TC, de similar sensibilidad, es más específica y permite, además, cuantificar la esteatosis y detectar esteatosis focal. En estudios sin contraste, los niveles de atenuación normales del hígado son de entre $50 \mathrm{UH}$ y $65 \mathrm{UH}$, y generalmente 8 UH a 10 UH más elevados que el bazo. Se han utilizado distintos puntos de corte para el diagnóstico de $\mathrm{EH}$; los más aceptados son los niveles de atenuación menores que un límite de entre 48 UH y 51 UH (y menores que el bazo). El grupo del estudio MESA, entre otros, utiliza una definición más sencilla que consiste en la presencia de un cociente de atenuación hígado (UH)/bazo (UH) $<$ 1. (62) Una atractiva particularidad de la TC es la capacidad de evaluar dentro de un mismo escaneo la porción superior/cúpula del parénquima hepático, la extensión y distribución de la calcificación coronaria y el TAE (Figura 4).

La RM es el método de mayor precisión para la evaluación de la $\mathrm{EH}$, si bien presenta menor disponibilidad, mayor costo y tiempo de adquisición, y dificultad para la evaluación de pacientes con IMC muy elevado o con claustrofobia. Cada una de estas tres modalidades ha evolucionado en los últimos años, y se han desarrollado técnicas específicas para la evaluación del HGNA, que exceden el presente artículo.

\section{Relación entre grasa epicárdica y cardiopatía no coronaria}

Algunos estudios han descripto una relación entre el TAE y la fibrilación auricular (FA). $(10,72)$ Si bien de mecanismos aún no definidos, ha sido atribuida a mecanismos probablemente mixtos vinculados en distinta medida no solo a la difusión de los productos proinflamatorios mencionados, sino a compresión mecánica externa con disminución de la complacencia, y a la afectación de propiedades diastólicas ventriculares a partir de fibrosis miocárdica. $(38,73)$ En un estudio que incluyó pacientes en plan de ablación, el volumen de grasa pericárdica (VGP) se asoció con la presencia y gravedad de la FA, así como de recurrencia; independientemente de parámetros generales de obesidad. (74) En paralelo, en un estudio reciente, van Woerden y cols. identificaron un mayor volumen de TAE en pacientes con ICFSP comparados con un grupo control, independientemente del IMC. Además, el TAE se asoció a la presencia de diabetes tipo 2, a la FA, y a diversos marcadores inflamatorios. (75) Se ha postulado incluso que la ICFSP con frecuencia identificada en pacientes obesos se puede atribuir a la presencia de disfunción microvascular y alteración de la relajación miocárdica vinculadas en distinta medida a la fibrosis miocárdica, dilatación y FA, y estado proinflamatorio observado en estos pacientes y asociado a un incremento del TAE. (76) El reciente hallazgo de una correlación significativa entre el TAE y tanto el contenido lipídico del miocardio como la fibrosis intersticial sugiere que efectivamente el TEA infiltra de algún modo el miocardio. (77)

Además, el TAE inflamado puede sintetizar aldosterona, que, a su vez, no solo perpetúa el estado inflamatorio y promueve la fibrosis, sino que también promueve la sobrecarga de volumen, lo que empeora en conjunto la ICFSP. (38)

\section{Relación entre los depósitos grasos regionales, ateromatosis y eventos}

La evidencia que vincula al TAE con marcadores de ateromatosis es consistente. Incluso algunos estudios sugieren que la ateromatosis acelerada comúnmente presente en pacientes VIH positivos podría atribuirse a 
la observación de un TAE aumentado en esta población. (78) Recientemente demostramos una relación significativa entre la grasa pericárdica y visceral con la carga de placa ateroesclerótica coronaria y extracoronaria, mientras que los marcadores generales de adiposidad, incluso el volumen de grasa corporal total calculada por TC, no se relacionaron con la carga ateroesclerótica. (49) Estos hallazgos se encuentran en línea con una gran cantidad de estudios que demostraron relaciones entre el TAE, y no los depósitos grasos generales, con marcadores de ateromatosis coronaria y extracoronaria independientemente de los FRC. (1, 3) En el Heinz Nixdorf Recall Study, que incluyó 4093 individuos de entre 45 y 75 años sin enfermedad cardiovascular conocida, los sujetos con TAE en el cuartil superior presentaron un riesgo significativamente mayor de eventos duros tras un seguimiento medio de 8 años, incluso tras el ajuste según FRC (HR 1,54; 95\% CI 1,09-2,19) y del score de calcio (HR 1,50; 95\% CI 1,07-2,11). (79) Este último hallazgo, en línea con resultados de otros estudios, apoya el concepto de que la relación entre la grasa epicárdica y los eventos vasculares tendría mecanismos distintos a los del riesgo vinculado a la calcificación coronaria. En una cohorte que incluyó 998 individuos de entre 45 y 85 años del estudio MESA, se encontró una asociación significativa entre el VGP y el riesgo de eventos coronarios, independientemente de los FRC y del IMC (HR 1,26; 95\% CI 1,01, 1,59), mientras que no se registraron relaciones significativas entre eventos e IMC o circunferencia abdominal. (80) En el Rancho Bernardo Study, un estudio de menor tamaño ( $n=343)$, pero de seguimiento a 12 años, los pacientes con VGP en el tertil superior presentaron un riesgo de mortalidad global 2,6 veces mayor que aquellos en el tertil inferior, independientemente de los FRC. (81) El estudio EISNER demostró en 456 individuos asintomáticos con edad media de 60 años, una relación significativa entre el TAE y la calcificación coronaria. (82) La capacidad predictiva del VGP evaluada por TC de tórax convencional también ha sido demostrada. En una cohorte retrospectiva que incluyó 1250 pacientes con TC de tórax clínicamente indicada, identificamos al VGP como predictor independiente de mortalidad de toda causa. (68)

\section{Relación entre la composición de la grasa y la manifestación de eventos}

La ACTC permite la evaluación de características de placas de alto riesgo (PAR), como el remodelamiento positivo, placas de baja atenuación $(<30 \mathrm{UH})$, signo de realce en anillo y microcalcificaciones. (83) Recientemente, Nerlekar y cols. publicaron un metaanálisis donde demostraron una relación entre la extensión de TAE y la presencia de PAR (OR 1,19 [95\% CI 1,06$1,33])$. (84)

Sin embargo, se estima que los cambios estructurales tanto coronarios como de la GPV pasibles de visualización mediante métodos como la TC indicarían estadios un poco más avanzados de la enfermedad que los cambios moleculares o funcionales. Esto ha llevado a la búsqueda de métodos no invasivos que permitan una detección más precoz de cambios metabólicos. Se ha mencionado antes que la distribución y composición del TAE no es homogénea, y que se asocia a la presencia y distribución de ateromatosis y al riesgo de eventos. Estos gradientes locales pueden ser discriminados con precisión por TC mediante la medición de la densidad (UH) de la GPV (la grasa de mayor densidad, más cercana al cero, reflejaría en distinta medida un menor contenido lipídico y la presencia de edema, mayor vascularización o fibrosis). (14-16)

Goeller y cols. reportaron niveles de atenuación de la GPV significativamente más elevados en lesiones culpables de pacientes con síndrome coronario agudo comparado con lesiones no culpables $(-69,1 \mathrm{UH}$ vs. $-74,8 \mathrm{UH} ; p=0,01$ ) e, incluso, comparado con lesiones graves de controles $(-76,4 \mathrm{UH} ; p=0,01)$. (85)

Se cree que estos cambios en la composición de la GPV (Figura 1) detectables por TC preceden a la formación de placas coronarias, y es de gran importancia la detección precoz, ya que la mayor parte de las roturas de placa y de eventos coronarios en general tienen como sustrato lesiones no obstructivas. $(14,15$, 83) En relación con esto y a partir de análisis complejos que incluyeron estudios genéticos, inmunomarcadores y evaluaciones tomográficas avanzadas (asistidos y posteriormente entrenados mediante herramientas de machine learning) basados en biopsias de cirugías cardíacas, con validación posterior en grandes estudios prospectivos; se identificaron patrones de atenuación de grasa pericoronaria (FAI) y un perfil radiotranscriptómico de la textura de la grasa pericoronaria (PRG) que reconocerían la presencia de inflamación coronaria. (15)

Utilizando dos grandes cohortes prospectivas de poblaciones completamente diferentes, este grupo de investigadores de Oxford validó al FAI como un marcador de inflamación coronaria asociado a mal pronóstico (Figura 6). En el estudio CRISP-CT, una FAI mayor (menos negativo) de $-70 \mathrm{UH}$ fue identificado como un robusto predictor de mortalidad cardíaca y de toda causa, independientemente de la demografía, del TAE, de la extensión de ateromatosis, y de la presencia de PAR. (14) En dicho estudio, el FAI, validado también contra el PET-TC, predijo la manifestación de eventos mayores incluso antes del desarrollo de placas. (37) El FAI (Figura 6) es un marcador no solo sensible, sino también dinámico de la inflamación coronaria, habiéndose demostrado su reducción con la administración de estatinas y aspirina. (14) La presencia de cambios crónicos en la GPV, vinculada a fibrosis y remodelamiento microvascular, puede ser valorada mediante la evaluación del perfil radiómico de la textura de la grasa asistido mediante algoritmos de machine learning (PRG). (86)

Estas características fueron validadas en 1575 pacientes del SCOT-HEART trial, donde mejoraron la predicción de eventos mayores más allá de los 
A

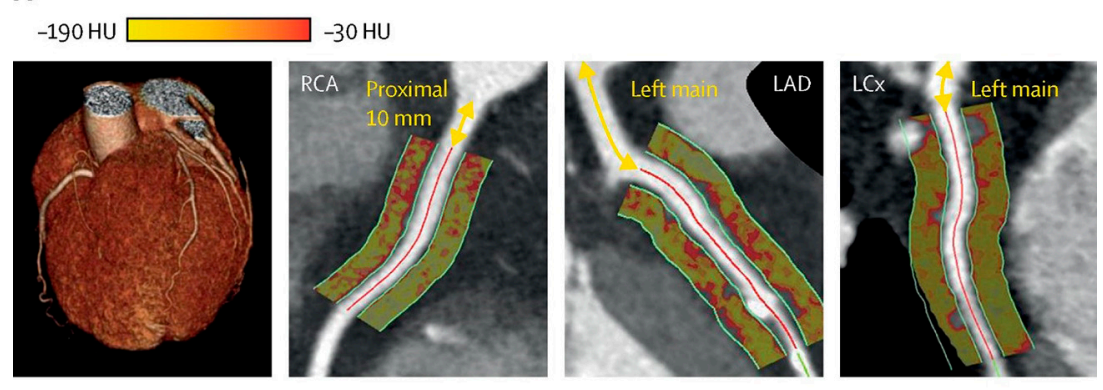

B

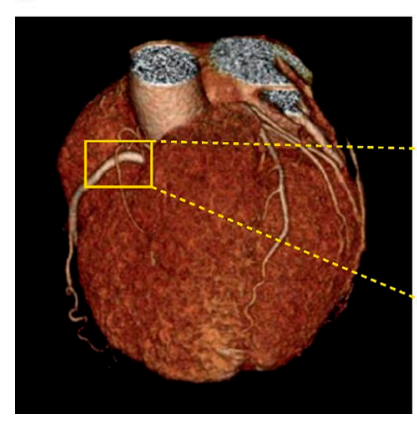

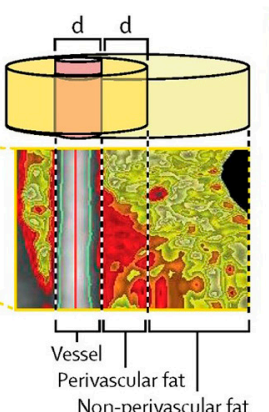

Non-nerivascular fat

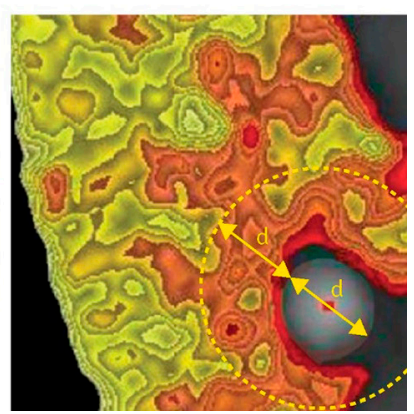

Fig. 6. A. Atenuación de la grasa pericoronaria (FAI) de los segmentos proximales de los tres vasos coronarios epicárdicos principales, con los mapas de FAl correspondientes. B. Ejemplo del fenotipo de la FAl pericoronaria alrededor del tercio proximal de la arteria coronaria derecha. Se definió a la grasa pericoronaria como a la grasa localizada a una distancia radial igual al diámetro (d) del vaso. HU: unidades Hounsfield, LAD: arteria descendente anterior, LCx: arteria circunfleja, RCA: coronaria derecha. (De: Oikonomou EK, et al. Lancet 2018, 392(10151):929-939).
FRC, del score de calcio, y de la gravedad y PAR determinadas por la ACTC. (15) Debe destacarse que tanto el FAI, que refleja cambios agudos (inflamación), como el PRG, que indica cambios estructurales crónicos, se obtienen a partir de adquisiciones convencionales de ACTC. Por lo tanto, estos métodos complementarios posiblemente puedan combinarse en un único estudio junto con las múltiples evaluaciones conocidas (y con valor pronóstico independiente) de la ACTC.

\section{Relación entre la esteatosis hepática y el riesgo cardiovascular}

La EH simple tiene un buen pronóstico. Sin embargo, los pacientes que desarrollan esteatohepatitis tienen mayor riesgo de progresar a enfermedad hepática crónica (fibrosis/cirrosis). (87) La edad (> 50 años), la diabetes tipo II, la obesidad y el síndrome metabólico se han identificado como factores asociados a la progresión de esteatosis simple a esteatohepatitis. (88) En pacientes con HGNA, la enfermedad cardiovascular es la causa más frecuente de muerte independientemente de los estadios de la enfermedad hepática. (89) Dicho incremento del riesgo cardiovascular ha sido vinculado a diversos mecanismos, que incluyen la promoción de la ateromatosis, arritmias y disfunción sistólica y diastólica. A pesar de ello, sigue vigente la controversia acerca de si la asociación entre HGNA y la enfermedad cardiovascular es una consecuencia de los múltiples factores de riesgo que comparten o si en su defecto el HGNA contribuye independientemente a la enfermedad cardiovascular. Además, si bien la esteatohepatitis se asocia a un incremento del riesgo de eventos, esta relación no se encuentra bien establecida en cuanto a la esteatosis simple (90).

En un reciente metaanálisis que incluyó 85395 pacientes de 26 estudios, el HGNA se asoció de forma independiente con la presencia de ateromatosis subclínica evaluada por Doppler carotídeo, score de calcio, rigidez arterial o disfunción endotelial (OR 1,6; $95 \%$ CI 1,45-1,78). (91) En particular, en los 13 estudios que incluyeron 12269 pacientes evaluados mediante Doppler carotídeo, el HGNA se asoció a un mayor riesgo de estudios patológicos (OR 1,74; $95 \%$ CI 1,47$2,06 ; p<0,00001)$; y, en los 7 estudios que incluyeron 29531 pacientes con TC sin contraste, el HGNA se asoció a un incremento en el score de calcio (OR 1,40; $95 \%$ CI 1,22-1,60; $p=0,02$ ). En otro metaanálisis, que incluyó 16 estudios y 34043 pacientes y una mediana de seguimiento de 6,9 años, Tagher y cols. identificaron una asociación significativa entre el HGNA y la manifestación de eventos cardiovasculares fatales o no fatales (HR 1,64, 95\% CI 1,26-2,13). (92) Además, los pacientes con HGNA grave (esteatosis y fibrosis) presentaron un incremento mayor en la mortalidad de origen cardiovascular (OR 3,28, 95\% CI 2,26-4,77), posiblemente vinculado a inflamación crónica. (92)

\section{Perspectivas futuras}

Una de las características interesantes del HGNA y diferenciales con respecto a la enfermedad coronaria es su carácter dinámico y, en cierta medida, reversible. Un descenso del 3\% del peso corporal se asocia a mejoría histológica en los pacientes con HGNA, si bien para que tenga impacto en la EHNA y la fibrosis el descenso de peso debe ser mayor del $7 \%$ y $10 \%$, respec- 
tivamente. A pesar de eso, aún se encuentra abierta la pregunta acerca de si la reducción en la esteatosis podría utilizarse como un marcador de reducción de riesgo cardiovascular.

Un aspecto interesante de la relación entre los depósitos grasos y los eventos cardiovasculares es la diferencia entre sexos. Es conocida la relación entre el sexo masculino y el riesgo de enfermedad cardiovascular. Si bien todavía no encuentran establecidos los mecanismos que los vinculan, las diferencias de riesgo entre sexos podrían atribuirse a que, a pesar de tener mayor contenido graso, las mujeres presentan una proporción de grasa visceral significativamente menor que los hombres, con mayor grasa subcutánea. (93) En conjunto, la evaluación de la extensión y composición de los depósitos grasos regionales podrían en un futuro próximo no solo ayudar a elucidar dichas diferencias de género, sino a mejorar y personalizar la estratificación de riesgo, identificando pacientes con riesgo residual elevado vinculado a inflamación. Entre todos los métodos diagnósticos disponibles, teniendo en cuenta su precisión, valoración cuantitativa y cualitativa, costo y disponibilidad; posiblemente la TC emerja como la modalidad más apropiada para la estratificación de riesgo, particularmente al permitir la evaluación conjunta de depósitos grasos y extensión de ateromatosis.

En cuanto a su factibilidad, la emergente incorporación de herramientas de cálculo automático asistidas por machine learning posiblemente permitan mediciones consistentes y reproducibles, independientemente del tipo de adquisición e interpretación, lo que facilitará su incorporación a la práctica clínica en un futuro próximo. (65)

A pesar de las asociaciones descriptas con la ateromatosis y con el riesgo cardiovascular, la grasa epicárdica y el HGNA son raramente considerados como marcadores de riesgo en la práctica clínica. Si bien no hay dudas a partir del estudio bioquímico, del riesgo que estos tejidos implican a la salud cardiovascular, la complejidad e inaccesibilidad para evaluarlos a partir de muestras de tejido dificulta su estudio. En virtud de la posibilidad de evaluarse de forma simultánea y complementaria dentro de una única modalidad de imagen no invasiva, como en el caso del score de calcio o la ACTC, podrían convertirse en un futuro próximo en herramientas pronósticas que permitan reflejar tanto el estado actual cardiometabólico y cambios dinámicos/ reversibles (esteatosis), como la presencia de cambios estructurales crónicos (calcificación coronaria). Parte de este carácter dinámico y diferencial entre la $\mathrm{EH}$ y el TEA se reflejó en un estudio reciente realizado con una población de 1250 pacientes de entre 35 y 74 años con TC de tórax sin contraste, donde, a pesar de encontrar asociaciones significativas entre la $\mathrm{EH}$ y tanto la calcificación coronaria (CAC) como el VGP, los únicos predictores de mortalidad de toda causa fueron la CAC y el VGE. (68)

\section{BIBLIOGRAFÍA}

1. Mahabadi AA, Lehmann N, Kalsch H, Bauer M, Dykun I, Kara K, et al. Association of epicardial adipose tissue and left atrial size on non-contrast CT with atrial fibrillation: the Heinz Nixdorf Recall Study. Eur Heart J Cardiovasc Imaging 2014;15:863-9. https://doi. org/10.1093/ehjci/jeu006

2. Mahabadi AA, Massaro JM, Rosito GA, Levy D, Murabito JM, Wolf $\mathrm{PA}$, et al. Association of pericardial fat, intrathoracic fat, and visceral abdominal fat with cardiovascular disease burden: the Framingham Heart Study. Eur Heart J2009;30:850-6. https://doi.org/10.1093/ eurheartj/ehn573

3. Rosito GA, Massaro JM, Hoffmann U, Ruberg FL, Mahabadi AA, Vasan RS, et al. Pericardial fat, visceral abdominal fat, cardiovascular disease risk factors, and vascular calcification in a community-based sample: the Framingham Heart Study. Circulation 2008, 117:605-13. https://doi.org/10.1161/CIRCULATIONAHA.107.743062

4. Sung KT, Kuo R, Sun JY, Hung TC, Chang SC, Liu CC, et al. Associations between CT-determined visceral fat burden, hepatic steatosis, circulating white blood cell counts and neutrophil-to-lymphocyte ratio. PloS One 2018; 13:e0207284. https://doi.org/10.1371/journal. pone.0207284

5. Barchuk M, Schreier L, López G, Cevey A, Baldi J, Fernández Tome MDC, et al. Glycosylphosphatidylinositol-anchored high density lipoprotein-binding protein 1 and angiopoietin-like protein 4 are associated with the increase of lipoprotein lipase activity in epicardial adipose tissue from diabetic patients. Atherosclerosis 2019;288:51-9. https://doi.org/10.1016/j.atherosclerosis.2019.06.915

6. Milanese G, Silva M, Bruno L, Goldoni M, Benedetti G, Rossi E, et al. Quantification of epicardial fat with cardiac CT angiography and association with cardiovascular risk factors in symptomatic patients: from the ALTER-BIO (Alternative Cardiovascular Bio-Imaging markers) registry. Diagnost Intervent Radiol 2019;25:35-41. https://doi. org/10.5152/dir.2018.18037

7. Li Y, Liu B, Li Y, Jing X, Deng S, Yan Y, et al. Epicardial fat tissue in patients with diabetes mellitus: a systematic review and meta-analysis. Cardiovasc Diabetol 2019;18:3. https://doi.org/10.1186/ s12933-019-0807-3

8. Hwang IC, Park HE, Choi SY. Epicardial Adipose Tissue Contributes to the Development of Non-Calcified Coronary Plaque: A 5-Year Computed Tomography Follow-up Study. J Atheroscler Thrombosis 2017;24:262-74. https://doi.org/10.5551/jat.36467

9. Rodríguez-Granillo GA, Carrascosa P, Deviggiano A, Capunay C, De Zan MC, Goldsmith A, et al. Pericardial fat volume is related to atherosclerotic plaque burden rather than to lesion severity. Eur Heart J Cardiovasc Imaging 2017; 18:795-801. https://doi.org/10.1093/ ehjci/jew139

10. Nakamori S, Nezafat M, Ngo LH, Manning WJ, Nezafat R. Left Atrial Epicardial Fat Volume Is Associated With Atrial Fibrillation: A Prospective Cardiovascular Magnetic Resonance 3D Dixon Study. J Am Heart Assoc 2018;7:e008232 https://doi.org/10.1161/ JAHA.117.008232

11. Zhu W, Zhang H, Guo L, Hong K. Relationship between epicardial adipose tissue volume and atrial fibrillation : A systematic review and meta-analysis. Herz 2016;41:421-7. https://doi.org/10.1007/ s00059-015-4387-z

12. Iantorno M, Soleimanifard S, Schar M, Brown TT, Bonanno G, Barditch-Crovo P, et al. Regional coronary endothelial dysfunction is related to the degree of local epicardial fat in people with HIV. Atherosclerosis 2018;278:7-14. https://doi.org/10.1016/j.atherosclerosis.2018.08.002

13. Nakanishi K, Fukuda S, Tanaka A, Otsuka K, Taguchi H, Shimada K. Relationships Between Periventricular Epicardial Adipose Tissue Accumulation, Coronary Microcirculation, and Left Ventricular Diastolic Dysfunction. Can J Cardiol 2017;33:1489-97. https://doi. org/10.1016/j.cjca.2017.08.001 
14. Oikonomou EK, Marwan M, Desai MY, Mancio J, Alashi A, Hutt Centeno E, et al. Non-invasive detection of coronary inflammation using computed tomography and prediction of residual cardiovascular risk (the CRISP CT study): a post-hoc analysis of prospective outcome data. Lancet 2018,392:929-39. https://oi.org/10.1016/ S0140-6736(18)31114-0

15. Oikonomou EK, Williams MC, Kotanidis CP, Desai MY, Marwan M, Antonopoulos AS, Thomas KE, Thomas S, Akoumianakis I, Fan LM et al: A novel machine learning-derived radiotranscriptomic signature of perivascular fat improves cardiac risk prediction using coronary CT angiography. Eur Heart J 2019;40:3529-43. https:/doi. org/10.1093/eurheartj/ehz592

16. Rodríguez-Granillo GA, Capunay C, Deviggiano A, De Zan M, Carrascosa P. Regional differences of fat depot attenuation using noncontrast, contrast-enhanced, and delayed-enhanced cardiac CT. Acta Radiol 2019;60:459-67. https://doi.org/10.1177/0284185118787356 17. Charlton MR, Burns JM, Pedersen RA, Watt KD, Heimbach JK, Dierkhising RA. Frequency and outcomes of liver transplantation for nonalcoholic steatohepatitis in the United States. Gastroenterol 2011;141:1249-53. https://doi.org/10.1053/j.gastro.2011.06.061

18. Yki-Jarvinen $\mathrm{H}$. Non-alcoholic fatty liver disease as a cause and a consequence of metabolic syndrome. Lancet Diabetes Endocrinol 2014;2:901-10. https://doi.org/10.1016/S2213-8587(14)70032-4 19. Ridker PM, Everett BM, Thuren T, MacFadyen JG, Chang WH, Ballantyne C, et al. Antiinflammatory Therapy with Canakinumab for Atherosclerotic Disease. N Engl J Med 2017;377:1119-31. https:// doi.org/10.1056/NEJMoa1707914

20. Bohula EA, Giugliano RP, Leiter LA, Verma S, Park JG, Sever PS, et al. Inflammatory and Cholesterol Risk in the FOURIER Trial. Circulation 2018;138:131-40. https://doi.org/10.1161/CIRCULATIONAHA.118.034032

21. Bhatt DL, Steg PG, Miller M, Brinton EA, Jacobson TA, Ketchum SB, et al. Cardiovascular Risk Reduction with Icosapent Ethyl for Hypertriglyceridemia. N Engl J Med 2019;380:11-22. https://doi. org/10.1056/NEJMoa1812792

22. Ortega FB, Lavie CJ, Blair SN. Obesity and Cardiovascular Disease. Circulation Res 2016;118:1752-70. https://doi.org/10.1161/ CIRCRESAHA.115.306883

23. Koliaki C, Liatis S, Kokkinos A. Obesity and cardiovascular disease: revisiting an old relationship. Metabolism: clinical and experimental 2019;92:98-107. https://doi.org/10.1016/j.metabol.2018.10.011 24. Mehta T, Fontaine KR, Keith SW, Bangalore SS, de los Campos G, Bartolucci A, Pajewski NM, Allison DB. Obesity and mortality: are the risks declining? Evidence from multiple prospective studies in the United States. Obes Rev 2014;15:619-29. https://doi.org/10.1111/ obr.12191

25. Sharma A, Vallakati A, Einstein AJ, Lavie CJ, Arbab-Zadeh A, López-Jiménez F, et al. Relationship of body mass index with total mortality, cardiovascular mortality, and myocardial infarction after coronary revascularization: evidence from a meta-analysis. Mayo Clin Proc 2014; 89:1080-100. https://doi.org/10.1016/j.mayocp.2014.04.020 26. Antonopoulos AS, Oikonomou EK, Antoniades C, Tousoulis D. From the BMI paradox to the obesity paradox: the obesity-mortality association in coronary heart disease. Obes Rev 2016;17:989-1000. https://doi.org/10.1111/obr.12440

27. Mukherjee D, Ojha C. Obesity Paradox in Contemporary Cardiology Practice. JACC Cardiovasc interv 2017;10:1293-4. https://doi. org/10.1016/j.jcin.2017.03.048

28. Wells JC. Commentary: The paradox of body mass index in obesity assessment: not a good index of adiposity, but not a bad index of cardio-metabolic risk. Int J Epidemiol 2014;43:672-4. https://doi. org/10.1093/ije/dyu060

29. Puig T, Ferrero-Gregori A, Roig E, Vázquez R, González-Juanatey JR, Pascual-Figal D, et al. Prognostic value of body mass index and waist circumference in patients with chronic heart failure (Spanish REDINSCOR Registry). Rev Esp Cardiol (Engl Ed) 2014; 67:101-6. https://doi.org/10.1016/j.recesp.2013.06.025
30. Rodríguez-Granillo GA, Carrascosa P. Abdominal Obesity as a Risk Predictor: Closer Than Body Mass Index But Not Close Enough. J Am Coll Cardiol 2018;71:1398-9. https://doi.org/10.1016/j.jacc.2017.12.065 31. Rao VN, Zhao D, Allison MA, Guallar E, Sharma K, Criqui MH, et al. Adiposity and Incident Heart Failure and its Subtypes: MESA (Multi-Ethnic Study of Atherosclerosis). JACC Heart Fail 2018;6:9991007. https://doi.org/10.1016/j.jchf.2018.07.009

32. Antonopoulos AS, Antoniades C. The role of epicardial adipose tissue in cardiac biology: classic concepts and emerging roles. J Physiol 2017;595:3907-17. https://doi.org/10.1113/JP273049

33. Iacobellis G. Epicardial fat: a new cardiovascular therapeutic target. Curr Opin Pharmacol 2016;27:13-8. https://doi.org/10.1016/j. coph.2016.01.004

34. Cherian S, Lopaschuk GD, Carvalho E. Cellular cross-talk between epicardial adipose tissue and myocardium in relation to the pathogenesis of cardiovascular disease. Am J Physiol Endocrinol Metabol 2012;303:E937-49. https://doi.org/10.1152/ajpendo.00061.2012

35. Fitzgibbons TP, Czech MP. Epicardial and perivascular adipose tissues and their influence on cardiovascular disease: basic mechanisms and clinical associations. J Am Heart Assoc 2014;3(2):e000582. https://doi.org/10.1161/JAHA.113.000582

36. Bucerius J, Mani V, Wong S, Moncrieff C, Izquierdo-García D, Machac J, et al. Arterial and fat tissue inflammation are highly correlated: a prospective 18F-FDG PET/CT study. Eur J Nucl Med Mol Imaging 2014;41:934-45. https://doi.org/10.1007/s00259-013-2653-y 37. Antonopoulos AS, Sanna F, Sabharwal N, Thomas S, Oikonomou EK, Herdman L, et al. Detecting human coronary inflammation by imaging perivascular fat. Sci Transl Med 2017;9:938. https://oi. org/10.1126/scitranslmed.aal2658

38. Packer M. Epicardial Adipose Tissue May Mediate Deleterious Effects of Obesity and Inflammation on the Myocardium. J Am Coll Cardiol 2018: 71:2360-72. https://doi.org/10.1016/j.jacc.2018.03.509

39. Viskovic K, Zidovec Lepej S, Gorenec A, Grgic I, Lukas D, et al. Cardiovascular markers of inflammation and serum lipid levels in HIV-infected patients with undetectable viremia. Sci Rep 2018;8:6113. https://doi.org/10.1038/s41598-018-24446-4

40. Lima-Martínez MM, Campo E, Salazar J, Paoli M, Maldonado I, Acosta C, et al. Epicardial fat thickness as cardiovascular risk factor and therapeutic target in patients with rheumatoid arthritis treated with biological and nonbiological therapies. Arthritis 2014;782850. https://doi.org/10.1155/2014/782850

41. Wang X, Guo Z, Zhu Z, Bao Y, Yang B. Epicardial fat tissue in patients with psoriasis: a systematic review and meta-analysis. Lipids Health Dis 2016, 15:103. https://doi.org/10.1186/s12944-016-0271-y 42. Chatzizisis YS, Giannoglou GD. Myocardial bridges spared from atherosclerosis: overview of the underlying mechanisms. Can J Cardiol 2009,25:219-22. https://doi.org/10.1016/S0828-282X(09)70065-0

43. Rodríguez-Granillo GA, Rosales MA, Pugliese F, FernándezPereira C, Rodríguez AE Prevalence and characteristics of major and minor coronary artery anomalies in an adult population assessed by computed tomography coronary angiography. EuroIntervention 2009;4:641-7. https://doi.org/10.4244/EIJV4I5A107

44. McKenney ML, Schultz KA, Boyd JH, Byrd JP, Alloosh M, Teague $\mathrm{SD}$, et al. Epicardial adipose excision slows the progression of porcine coronary atherosclerosis. J Cardiothorac Surg 2014;9:2. https://doi. org/10.1186/1749-8090-9-2

45. Hirata Y, Tabata M, Kurobe H, Motoki T, Akaike M, Nishio C, et al. Coronary atherosclerosis is associated with macrophage polarization in epicardial adipose tissue. J Am Coll Cardiol 2011;58:248-55. https://doi.org/10.1016/j.jacc.2011.01.048

46. Miksztowicz V, Morales C, Barchuk M, López G, Poveda R, Gelpi $\mathrm{R}$, et al. Metalloproteinase 2 and 9 Activity Increase in Epicardial Adipose Tissue of Patients with Coronary Artery Disease. Curr Vasc Pharmacol 2017;15:135-43. https://doi.org/10.2174/1570161114666 161024124244

47. Bouchi R, Takeuchi T, Akihisa M, Ohara N, Nakano Y, Nishitani $\mathrm{R}$, et al: High visceral fat with low subcutaneous fat accumulation 
as a determinant of atherosclerosis in patients with type 2 diabetes. Cardiovasc Diabetol 2015;14:136. https://doi.org/10.1186/s12933015-0302-4

48. Ladeiras-Lopes R, Sampaio F, Bettencourt N, Fontes-Carvalho R, Ferreira N, Leite-Moreira A, et al. The Ratio Between Visceral and Subcutaneous Abdominal Fat Assessed by Computed Tomography Is an Independent Predictor of Mortality and Cardiac Events. Rev Esp Cardiol (Engl Ed) 2017;70:331-7. https://doi.org/10.1016/j. recesp.2016.09.006

49. Rodríguez-Granillo GA, Reynoso E, Capunay C, Carpio J, Carrascosa P. Pericardial and visceral, but not total body fat, are related to global coronary and extra-coronary atherosclerotic plaque burden. Int J Cardiol 2018;260:204-10. https://doi.org/10.1016/j.ijcard.2018.01.106 50. Mazurek T, Zhang L, Zalewski A, Mannion JD, Diehl JT, Arafat $\mathrm{H}$, et al: Human epicardial adipose tissue is a source of inflammatory mediators. Circulation 2003;108:2460-6. https://doi.org/10.1161/01. CIR.0000099542.57313.C5

51. Barchuk M, Dutour A, Ancel P, Svilar L, Miksztowicz V, Lopez G, et al. Untargeted Lipidomics Reveals a Specific Enrichment in Plasmalogens in Epicardial Adipose Tissue and a Specific Signature in Coronary Artery Disease. Arterioscl Thromb Vasc Biol 2020;40:9861000. https://doi.org/10.1161/ATVBAHA.120.313955

52. Donnelly KL, Smith CI, Schwarzenberg SJ, Jessurun J, Boldt MD, Parks EJ. Sources of fatty acids stored in liver and secreted via lipoproteins in patients with nonalcoholic fatty liver disease. J Clin investig 2005;115:1343-51. https://doi.org/10.1172/JCI23621

53. Chalasani N, Younossi Z, Lavine JE, Charlton M, Cusi K, Rinella M, et al. The diagnosis and management of nonalcoholic fatty liver disease: Practice guidance from the American Association for the Study of Liver Diseases. Hepatol 2018; 67:328-57. https://doi. org/10.1002/hep.29367

54. Gastaldelli A, Toschi E, Pettiti M, Frascerra S, Quinones-Galvan A, Sironi AM, et al. Effect of physiological hyperinsulinemia on gluconeogenesis in nondiabetic subjects and in type 2 diabetic patients. Diabetes 2001;50:1807-12. https://doi.org/10.2337/diabetes.50.8.1807

55. Bugianesi E, Gastaldelli A, Vanni E, Gambino R, Cassader M, Baldi S. Insulin resistance in non-diabetic patients with non-alcoholic fatty liver disease: sites and mechanisms. Diabetol 2005;48:634-42. https://doi.org/10.1007/s00125-005-1682-x

56. Gaggini M, Morelli M, Buzzigoli E, DeFronzo RA, Bugianesi E, Gastaldelli A. Non-alcoholic fatty liver disease (NAFLD) and its connection with insulin resistance, dyslipidemia, atherosclerosis and coronary heart disease. Nutrients 2013;5:1544-60. https://doi. org/10.3390/nu5051544

57. Luo ZX, Zeng Q, Luo R, Wang Y, Ge Q. Relative Contributions of Ectopic Liver and Abdominal Fat Accumulation to Arterial Stiffness. Endocr Pract 2015; 21:574-80. https://doi.org/10.4158/EP14526.OR

58. Lucero D, Zago V, López GI, Graffigna M, López GH, Fainboim $\mathrm{H}$, et al. Does non-alcoholic fatty liver impair alterations of plasma lipoproteins and associated factors in metabolic syndrome? Clin Chim Acta 2011;412:587-92. https://doi.org/10.1016/j.cca.2010.12.012

59. Lucero D, Miksztowicz V, Gualano G, Longo C, Landeira G, Álvarez $\mathrm{E}$, et al. Nonalcoholic fatty liver disease associated with metabolic syndrome: Influence of liver fibrosis stages on characteristics of very low-density lipoproteins. Clin Chim Acta 2017;473:1-8. https://doi. org/10.1016/j.cca.2017.08.006

60. Stefan N, Kantartzis K, Haring HU. Causes and metabolic consequences of Fatty liver. Endocrin Rev 2008;29:939-60. https://doi. org/10.1210/er.2008-0009

61. Targher G, Chonchol M, Miele L, Zoppini G, Pichiri I, Muggeo M. Nonalcoholic fatty liver disease as a contributor to hypercoagulation and thrombophilia in the metabolic syndrome. Semin Thromb Hemost 2009;35:277-87. https://doi.org/10.1055/s-0029-1222606

62. Simon TG, Trejo MEP, McClelland R, Bradley R, Blaha MJ, Zeb I, et al. Circulating Interleukin-6 is a biomarker for coronary atherosclerosis in nonalcoholic fatty liver disease: Results from the Multi-Ethnic Study of Atherosclerosis. Int J Cardiol 2018;259:198204. https://doi.org/10.1016/j.ijcard.2018.01.046
63. Campbell PT, VanWagner LB, Colangelo LA, Lewis CE, Henkel A, Ajmera VH, et al. Association between plasminogen activator inhibitor-1 in young adulthood and nonalcoholic fatty liver disease in midlife: CARDIA. Liver int 2020;40:1111-20. https://doi.org/10.1111/ liv. 14417

64. Marwan M, Achenbach S. Quantification of epicardial fat by computed tomography: why, when and how? J Cardiovasc Comput Tomogr 2013,7:3-10. https://doi.org/10.1016/j.jcct.2013.01.002

65. Commandeur F, Goeller M, Razipour A, Cadet S, Hell MM, Kwiecinski J, et al. Fully Automated CT Quantification of Epicardial Adipose Tissue by Deep Learning: A Multicenter Study. Radiol Artif intellig 2019;1:e190045. https://doi.org/10.1148/ryai.2019190045

66. La Grutta L, Toia P, Farruggia A, Albano D, Grassedonio E, Palmeri A, et al.Quantification of epicardial adipose tissue in coronary calcium score and CT coronary angiography image data sets: comparison of attenuation values, thickness and volumes. $\mathrm{Br}$ J Radiol 2016;89:20150773. https://doi.org/10.1259/bjr.20150773

67. Nagayama Y, Nakamura N, Itatani R, Oda S, Kusunoki S, Takahashi $\mathrm{H}$, et al. Epicardial fat volume measured on nongated chest CT is a predictor of coronary artery disease. Eur Radiol 2019;29:3638-46. https://doi.org/10.1007/s00330-019-06079-x

68. Rodríguez-Granillo GA, Reynoso E, Capunay C, Antoniades C, Shaw LJ, Carrascosa P. Prognostic Value of Vascular Calcifications and Regional Fat Depots Derived From Conventional Chest Computed Tomography. J Thoracic Imaging 2019;34:33-40. https://doi. org/10.1097/RTI.0000000000000370

69. Iacobellis G, Corradi D, Sharma AM. Epicardial adipose tissue: anatomic, biomolecular and clinical relationships with the heart. Nat Clin Pract Cardiovasc Med 2005;2:536-43. https://doi.org/10.1038/ ncpcardio0319

70. Cheng VY, Dey D, Tamarappoo B, Nakazato R, Gransar H, Miranda-Peats R, et al. Pericardial fat burden on ECG-gated noncontrast $\mathrm{CT}$ in asymptomatic patients who subsequently experience adverse cardiovascular events. JACC Cardiovasc Imaging 2010;3:352-60. https://doi.org/10.1016/j.jcmg.2009.12.013

71. Li Q, Dhyani M, Grajo JR, Sirlin C, Samir AE.Current status of imaging in nonalcoholic fatty liver disease. World J Hepatol 2018;10:530-42. https://doi.org/10.4254/wjh.v10.i8.530

72. Al Chekakie MO, Welles CC, Metoyer R, Ibrahim A, Shapira AR, Cytron J,et al. Pericardial fat is independently associated with human atrial fibrillation. J Am Coll Cardiol2010;56:784-8. https://doi. org/10.1016/j.jacc.2010.03.071

73. Iacobellis G, Leonetti F, Singh N, A MS.Relationship of epicardial adipose tissue with atrial dimensions and diastolic function in morbidly obese subjects. Int J Cardiol 2007;115:272-3. https://oi. org/10.1016/j.ijcard.2006.04.016

74. Wong CX, Abed HS, Molaee P, Nelson AJ, Brooks AG, Sharma G, et al. Pericardial fat is associated with atrial fibrillation severity and ablation outcome. J Am Coll Cardiol 2011;57:1745-51. https://doi. org/10.1016/j.jacc.2010.11.045

75. van Woerden G, Gorter TM, Westenbrink BD, Willems TP, van Veldhuisen DJ, Rienstra M. Epicardial fat in heart failure patients with mid-range and preserved ejection fraction. Eur J Heart Fail 2018;20:1559-66. https://doi.org/10.1002/ejhf.1283

76. Venteclef N, Guglielmi V, Balse E, Gaborit B, Cotillard A, Atassi $\mathrm{F}$, et al. Human epicardial adipose tissue induces fibrosis of the atrial myocardium through the secretion of adipo-fibrokines. Eur Heart J 2015;36:795-805a. https://doi.org/10.1093/eurheartj/eht099

77. Ng ACT, Strudwick M, van der Geest RJ, Ng ACC, Gillinder L, Goo SY, et al. Impact of Epicardial Adipose Tissue, Left Ventricular Myocardial Fat Content, and Interstitial Fibrosis on Myocardial Contractile Function. Circulation Cardiovasc Imaging 2018:11:e007372. https://doi.org/10.1161/CIRCIMAGING.117.007372

78. Brener M, Ketlogetswe K, Budoff M, Jacobson LP, Li X, Rezaeian $\mathrm{P}$, et al. Epicardial fat is associated with duration of antiretroviral therapy and coronary atherosclerosis. Aids 2014;28:1635-44. https:// doi.org/10.1097/QAD.0000000000000116

79. Mahabadi AA, Berg MH, Lehmann N, Kalsch H, Bauer M, Kara K, 
et al. Association of epicardial fat with cardiovascular risk factors and incident myocardial infarction in the general population: the Heinz Nixdorf Recall Study. J Am Coll Cardiol 2013;61:1388-95. https://doi. org/10.1016/j.jacc.2012.11.062

80. Ding J, Hsu FC, Harris TB, Liu Y, Kritchevsky SB, Szklo M, et al: The association of pericardial fat with incident coronary heart disease: the Multi-Ethnic Study of Atherosclerosis (MESA). Am J Clin Nut 2009;90:499-504. https://doi.org/10.3945/ajcn.2008.27358 81. Larsen BA, Laughlin GA, Saad SD, Barrett-Connor E, Allison MA, Wassel CL. Pericardial fat is associated with all-cause mortality but not incident CVD: the Rancho Bernardo Study. Atherosclerosis 2015;239:470-5. https://doi.org/10.1016/j.atherosclerosis.2015.02.022

82. Goeller M, Achenbach S, Marwan M, Doris MK, Cadet S, Commandeur F, et al. Epicardial adipose tissue density and volume are related to subclinical atherosclerosis, inflammation and major adverse cardiac events in asymptomatic subjects. J Cardiovasc Comp Tomogr 2018;12:67-73. https://doi.org/10.1016/j.jcct.2017.11.007

83. Rodríguez-Granillo GA, Carrascosa P, Bruining N, Waksman R, García-García HM. Defining the non-vulnerable and vulnerable patients with computed tomography coronary angiography: evaluation of atherosclerotic plaque burden and composition. Eur Heart J Cardiovasc Imaging 2016;17:481-91. https://doi.org/10.1093/ehjci/jew012 84. Nerlekar N, Brown AJ, Muthalaly RG, Talman A, Hettige T, Cameron JD, et al. Association of Epicardial Adipose Tissue and High-Risk Plaque Characteristics: A Systematic Review and MetaAnalysis. J Am Heart Assoc 2017;6:e006379. https://doi.org/10.1161/ JAHA.117.006379

85. Goeller M, Achenbach S, Cadet S, Kwan AC, Commandeur F, Slomka PJ, et al. Pericoronary Adipose Tissue Computed Tomography Attenuation and High-Risk Plaque Characteristics in Acute Coronary
Syndrome Compared With Stable Coronary Artery Disease. JAMA Cardiol 2018:3:858-63. https://doi.org/10.1001/jamacardio.2018.1997 86. Oikonomou EK, Antoniades C. The role of adipose tissue in cardiovascular health and disease. Nat Rev Cardiol 2019;16:83-99. https://doi.org/10.1038/s41569-018-0097-6

87. Rinella ME. Nonalcoholic fatty liver disease: a systematic review. JAMA 2015;313:2263-73. https://doi.org/10.1001/jama.2015.5370

88. McPherson S, Hardy T, Henderson E, Burt AD, Day CP, Anstee QM. Evidence of NAFLD progression from steatosis to fibrosingsteatohepatitis using paired biopsies: implications for prognosis and clinical management. J Hepatol 2015; 62:1148-55. https://doi. org/10.1016/j.jhep.2014.11.034

89. Ekstedt M, Franzen LE, Mathiesen UL, Thorelius L, Holmqvist M, Bodemar G, et al. Long-term follow-up of patients with NAFLD and elevated liver enzymes. Hepatology 2006;44:865-73. https://oi. org/10.1002/hep. 21327

90. Targher G, Day CP, Bonora E. Risk of cardiovascular disease in patients with nonalcoholic fatty liver disease. New Engl J Med 2010;363:1341-50. https://doi.org/10.1056/NEJMra0912063

91. Zhou YY, Zhou XD, Wu SJ, Fan DH, Van Poucke S, Chen YP, et al. Nonalcoholic fatty liver disease contributes to subclinical atherosclerosis: A systematic review and meta-analysis. Hepatol Commun 2018;2:376-92. https://doi.org/10.1002/hep4.1155

92. Targher G, Byrne CD, Lonardo A, Zoppini G, Barbui C. Nonalcoholic fatty liver disease and risk of incident cardiovascular disease: A meta-analysis. J Hepatol 2016:65:589-600. https://doi.org/10.1016/j. jhep.2016.05.013

93. Camhi SM, Bray GA, Bouchard C, Greenway FL, Johnson WD, Newton RL, et al. The relationship of waist circumference and BMI to visceral, subcutaneous, and total body fat: sex and race differences. Obesity 2011;19:402-8.https://doi.org/10.1038/oby.2010.248 